Check for updates

Cite this: J. Mater. Chem. C, 2021, 9, 3065

Received 27th November 2020 Accepted 13th January 2021

DOI: $10.1039 / \mathrm{dOtc05598k}$

rsc.li/materials-c

\section{Influencing prototropy by metal ion coordination: supramolecular transformation of a dynamer into a $\mathrm{Zn}$-based toroidal species $\uparrow+$}

\author{
Miroslava Čonková, (D) ab Wojciech Drożdż, (D) ab Zygmunt Miłosz, (D) c \\ Piotr Cecot, (D) ab Jack Harrowfield, (D) ${ }^{d}$ Mikotaj Lewandowski (D) ${ }^{c}$ and \\ Artur R. Stefankiewicz (D)*ab
}

\begin{abstract}
Disruption of a tautomeric equilibrium by coordination self-assembly depends upon a delicate interplay between supramolecular interactions but has not been studied for supramolecular polymers in two dimensions at the solid-liquid interface. Presented herein is the description of a functionalized molecular module which in DMSO solution generates a highly compact dynamic aggregate in its lactam (amide) form that undergoes reaction with $\mathrm{Zn}(\mathrm{II})$ ion to give a $\mathrm{ML}_{2}$ type complex in which one lactam unit on each ligand has been converted to its iminol form, enabling bidentate binding also involving pyrimidine- $\mathrm{N}$. These solution measurements, as well as a study by scanning tunneling microscopy at the liquid/graphite interface, corroborated by density functional studies, have revealed how the tautomeric equilibrium can be modulated by the addition of a metal salt.
\end{abstract}

Supramolecular assemblies based on noncovalent bonds are reversible and sensitive to environment, entailing adaptivity and stimuli-responsiveness that can be employed to achieve desired topology and/or functionality. ${ }^{1-7}$ Of the numerous stimuli which have been used to displace dynamic equilibria, ${ }^{8,9}$ metal ions are amongst the most versatile, since their actual influence can vary greatly, depending upon the particular choice. ${ }^{10}$ Very simple, long-known examples of their varying preferences for interaction sites are provided by the complexes of transition metals with ambidentate ligands ${ }^{11-13}$ such as thiocyanate and nitrite ions, although more interesting cases arise with the coordination of primary amides, RCONHR ${ }^{\prime 14-17}$ In their neutral

\footnotetext{
${ }^{a}$ Faculty of Chemistry, Adam Mickiewicz University, Uniwersytetu Poznańskiego 8, Poznań 61-614, Poland. E-mail: ars@amu.edu.pl

${ }^{b}$ Center for Advanced Technologies, Adam Mickiewicz University, Uniwersytetu Poznańskiego 10, Poznań 61-614, Poland

${ }^{c}$ NanoBioMedical Centre, Adam Mickiewicz University, Wszechnicy Piastowskiej 3, Poznań 61-614, Poland

${ }^{d}$ Institut de Science et d'Ingénierie Supramoléculaires (ISIS), Université de Strasbourg, 8 allée Gaspard Monge, Strasbourg 67083, France

$\dagger$ Electronic supplementary information (ESI) available. See DOI: 10.1039/ d0tc05598k

\# Dedicated to Prof. Bogdan Marciniec on the occasion of his 80th birthday.
}

form, such amides behave as O-donor species but the enhancement of acidity due to their coordination results in their ready deprotonation followed by rearrangement to the N-bound anion, subsequent reacidification leading, at least in the case of kinetically inert $\mathrm{Co}(\mathrm{III}),{ }^{18}$ to a complex of the tautomeric iminol form of the neutral ligand.

Similar cases of metal ion binding leading to displacement of a tautomeric equilibrium have been seen in uranyl ion complexes of amidoximes, where the ligand is bound in its neutral but zwitterionic form obtained by proton transfer from O to oxime-N. ${ }^{19,20}$ Somewhat surprisingly therefore, these principles have not been explored for more complex dynamic aggregates in solution and in two dimensions on a flat surface, even though structurally distinct supramolecular assemblies can be efficiently studied in submolecular detail with scanning probe techniques. ${ }^{21,22}$

In seeking to explore enhancement of metal ion effects on a tautomeric equilibrium, we have examined the coordination behavior of the 2-pyridone-derived ligand $\mathbf{H}_{2} \mathbf{L}$ (Fig. 1), where the additional pyrimidine- $\mathrm{N}$ coordination sites adjacent to the amide unit were expected to favor action as a bis(bidentate) species with the amide units converted to their iminol form, thus making the bidentate unit a 2,2'-bipyridine derivative. Both theoretical and experimental studies of 2-pyridone itself have shown that its lactam and iminol forms do not differ greatly in energy, so that the position of the equilibrium between them is readily displaced. ${ }^{23,24}$ The ligand $\left(\mathbf{H}_{2} \mathbf{L}\right)$ was prepared in three steps, following a previously reported procedure ${ }^{25}$ The molecule is insoluble in the most commonly used solvents except for dimethyl sulfoxide (DMSO). While it would appear possible that $\mathbf{H}_{\mathbf{2}} \mathbf{L}$ could adopt a multitude of different forms (for other possible tautomeric forms for ligand $\mathbf{H}_{2} \mathbf{L}$ and coordination modes see Fig. S1 and S2 in the ESI $\dagger$ ), previous study ${ }^{25}$ by ${ }^{1} \mathrm{H}$ NMR spectroscopy of the molecule in DMSO solution and by STM when adsorbed (from 1,2,4trichlorobenzene) on graphite, has shown only the form presented in Fig. 1 to be involved. Features of the ambient-temperature 


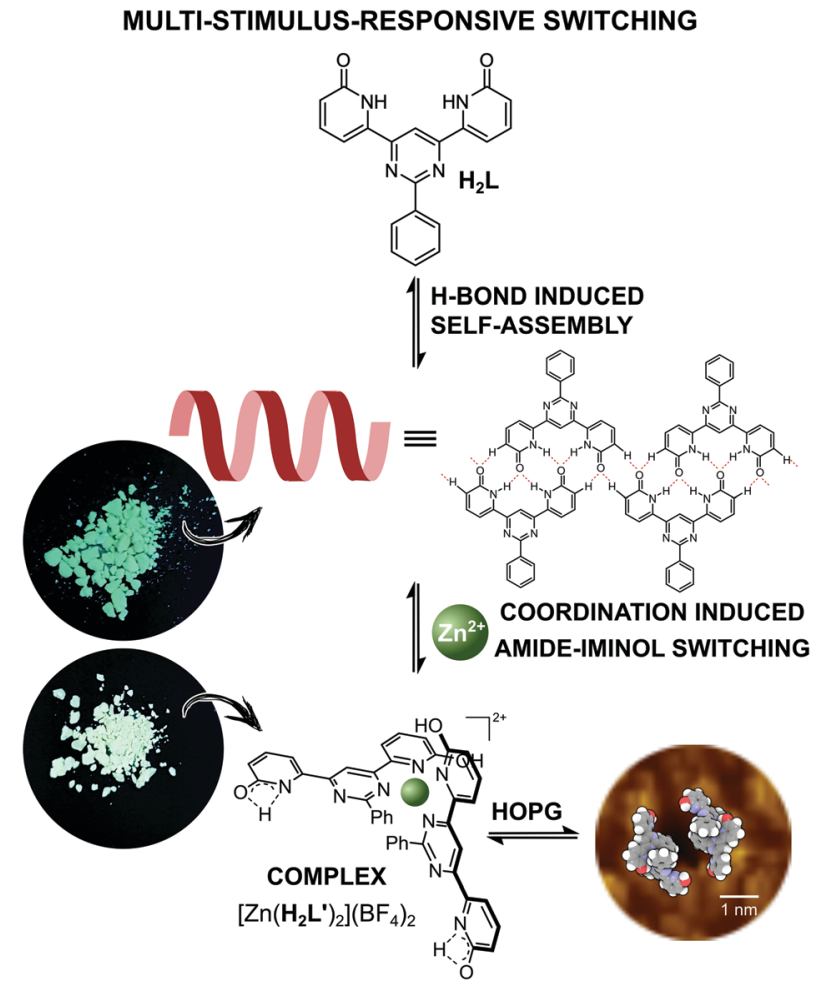

Fig. 1 Schematic representation of the metal-ion coordination induced supramolecular transformation between organic dynamer and $\mathrm{Zn}$-based $M L_{2}$ type complex

${ }^{1} \mathrm{H}$ NMR spectroscopy in DMSO (Fig. 2a), not previously commented on, are that the peaks are all rather broad and that the $\mathrm{NH}$ resonance appears at a rather low field (11.5 ppm) indicating its involvement in $\mathrm{H}$-bonding interactions.

Since intramolecular H-bonding is not possible for the conformer shown in Fig. 1, this is taken as evidence that supramolecular aggregation due primarily to $\mathrm{N}-\mathrm{H} \cdots \mathrm{O}$ type hydrogen bonding, to some extent analogous to that seen on graphite, must also occur in solution.

In contrast, the ${ }^{1} \mathrm{H}$ NMR spectrum in DMSO- $d_{6}$, of the $O$-methylated analogue of $\mathbf{H}_{2} \mathbf{L}$, which cannot form hydrogenbonded structures and can exists only in pseudo-iminol form, is markedly different and appears as sharp, well-resolved proton signals expected for the monomeric structures containing two methoxypyridine units (see Fig. S3 in the ESI $\dagger$ ). Moreover, MALDI mass spectrometry provided further evidence for the presence of $\mathbf{H}_{2} \mathbf{L}$-based supramolecular H-bonded aggregates (Fig. 3a), while only the monomer signal was observed for the reference $O$-methylated component (see Fig. S4 in the ESI $\dagger$ ).

Interestingly, when, as part of the present work, the DMSO solution was titrated with aqueous $\mathrm{HCl}$ to see if protonation might disrupt this aggregation, the spectrum remained essentially unchanged except for the disappearance of the NH signal (Fig. S5, in the ESI $\dagger$ ). The lack of evidence of protonation is unsurprising given the weak basicity of both pyrimidine and amide units but the loss of the $\mathrm{NH}$ peak could be explained as a result of an acid-catalyzed exchange process passing through the iminol (hydroxypyridine) tautomer of $\mathbf{H}_{2} \mathbf{L}$ as an intermediate (Fig. S6 in the ESI $\dagger$ ), thus being evidence that this form should be attainable and justifying efforts to explore the effects of metal ion coordination.

While it is known that different metal ions can favour binding of either tautomer of an amide ligand, ${ }^{17,26} \mathrm{Zn}$ (II), in particular has been shown to favour the iminol form.

The diamagnetic nature of $\mathrm{Zn}$ (II) renders ${ }^{1} \mathrm{H}$ NMR spectroscopy a particularly convenient way of following its complex formation. Addition of $\mathrm{Zn}\left(\mathrm{BF}_{4}\right)_{2}$ to a solution of $\mathbf{H}_{2} \mathbf{L}$ in DMSO$d_{6}$ produced no immediate change in the ${ }^{1} \mathrm{H}$ NMR spectrum but on prolonged reaction (48 hours) at a high temperature, peaks, in particular two broad resonances at $\delta 11.3$ and 11.8, attributable to a new species became evident (Fig. S7 in the ESI $\dagger$ ). Assuming that the slowness of the reaction was due to the limited ability of the neutral, amide-form ligand to compete with DMSO for coordination to $\mathrm{Zn}$ (II), an alternative means of bringing the two species into contact was sought.

The NH acidity of primary amides is well-known, the $\mathrm{p} K_{\mathrm{a}}$ of 2-pyridone itself in DMSO being $17,{ }^{27}$ and an anionic ligand should of course interact more strongly with a cation than it would with its neutral parent. Even more significantly, there is an extensive known coordination chemistry of amide-derived anions which shows that the form of their complexes is usually closer to what would be expected for an iminolate than an amidate. $^{27,28}$ Reaction of $\mathbf{H}_{\mathbf{2}} \mathbf{L}$ with 2 molar equivalents of $\mathrm{NaOH}$ in DMSO- $d_{6}$ provided a deep yellow solution giving a

a)
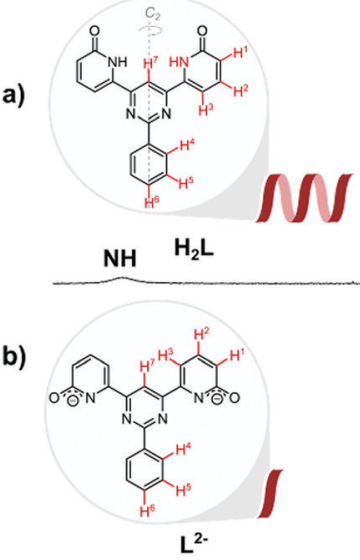

c)

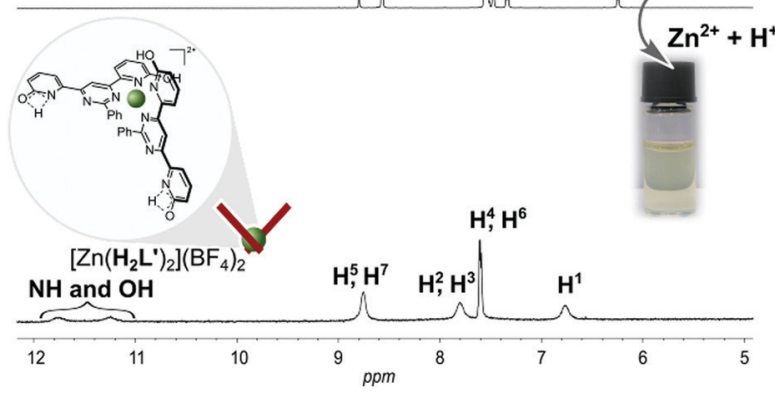

Fig. $2{ }^{1} \mathrm{H}$ NMR (600 MHz) spectra at ambient temperature of: (a) fully organic dynamer $\mathrm{H}_{\mathbf{2}} \mathrm{L}$; (b) $\mathrm{L}^{2-}$ in form of disodium salt; (c) $\left[\mathrm{Zn}\left(\mathrm{H}_{\mathbf{2}} \mathrm{L}^{\prime}\right)_{2}\right]\left(\mathrm{BF}_{4}\right)_{2}$ in DMSO- $d_{6}$. 


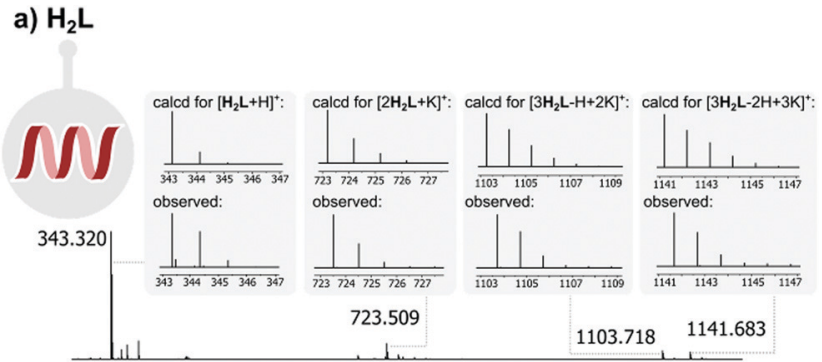

b) $\left[\mathrm{Zn}\left(\mathrm{H}_{2} \mathrm{~L}^{\prime}\right)_{2}\right]\left(\mathrm{BF}_{4}\right)_{2}$

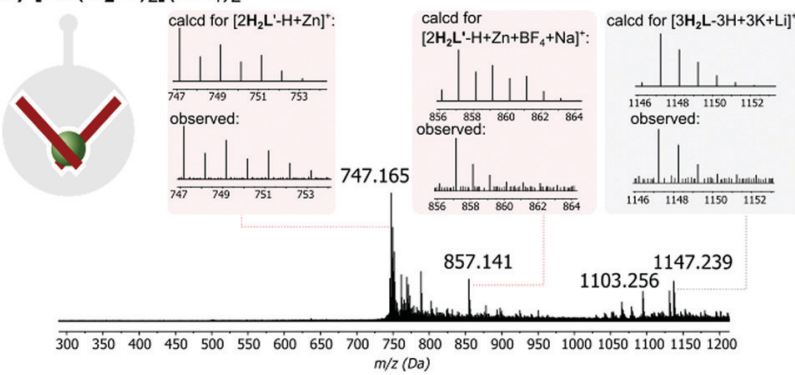

Fig. 3 Simulated and experimental MALDI-MS signals of: (a) $H_{2} L$ and (b) complex $\left[\mathrm{Zn}\left(\mathrm{H}_{2} \mathrm{~L}^{\prime}\right)_{2}\right]\left(\mathrm{BF}_{4}\right)_{2}$.

${ }^{1} \mathrm{H}$ NMR spectrum with very well resolved peaks consistent with the formation of the presumably largely dissociated disodium complex (Fig. 2b). Addition of 0.5 molar equivalent of $\mathrm{Zn}\left(\mathrm{BF}_{4}\right)_{2}$ to this solution resulted in drastic broadening of all peaks, indicating rather strong interaction, and careful addition of 2 molar equivalents of $\mathrm{HCl}$ then led to the emergence of two broad resonances as seen in the first experiment (Fig. 2c). Assignment of one of these resonances as due to the $\mathrm{NH}$ of the uncoordinated amide unit and the other as $\mathrm{OH}$ of the bound iminol unit is completely consistent with the structure shown in Fig. 2, although we have not been able to establish which is which.

Repetition of the second experiment on a preparative scale and addition of methanol and diethyl ether to the final solution led to the isolation of $\left[\mathrm{Zn}\left(\mathbf{H}_{2} \mathbf{L}^{\prime}\right)_{2}\right]\left(\mathrm{BF}_{4}\right)_{2}$ in the form of yellow powder.

Since a $2,2^{\prime}$-bipyridine-like ligand should be weakly basic and $\mathrm{Zn}$ (II) complexes are generally labile, we reasoned that release of the ligand from $\left[\mathrm{Zn}\left(\mathbf{H}_{2} \mathbf{L}^{\prime}\right)_{2}\right]\left(\mathrm{BF}_{4}\right)_{2}$ should occur on further addition of acid. Consistent with this expectation, an ${ }^{1} \mathrm{H}$ NMR titration of $\left[\mathrm{Zn}\left(\mathbf{H}_{2} \mathbf{L}^{\prime}\right)_{2}\right]\left(\mathrm{BF}_{4}\right)_{2}$ with acid $(0.06 \mathrm{M} \mathrm{HCl}$, in $\mathrm{H}_{2} \mathrm{O} /$ DMSO- $d_{6}$ ) revealed, after addition of 1 equivalent, that the spectrum of dynamer $\mathbf{H}_{2} \mathbf{L}$ was regenerated (see ESI, $\dagger$ Fig. S13). Since chloride ion is poorly solvated in DMSO, formation of chloro complexes may have assisted this reaction also.

Since in DMSO solution, $\left[\mathrm{Zn}\left(\mathbf{H}_{2} \mathbf{L}^{\prime}\right)_{2}\right]\left(\mathrm{BF}_{4}\right)_{2}$ has a rather dynamic nature, we decided to examine fluorescence of both $\mathbf{H}_{2} \mathbf{L}$ and $\left[\mathrm{Zn}\left(\mathbf{H}_{2} \mathbf{L}^{\prime}\right)_{2}\right]\left(\mathrm{BF}_{4}\right)_{2}$ in solid state. These measurements show that described system is photo-responsive, which opens several avenues towards their application in various technological fields. As shown in Fig. 4, after excitation at $468 \mathrm{~nm}$, the emission spectrum of $\mathbf{H}_{2} \mathbf{L}$ shows a broad band with its maximum at $555 \mathrm{~nm}$, while in the emission spectrum of $\left[\mathrm{Zn}\left(\mathbf{H}_{2} \mathbf{L}^{\prime}\right)_{2}\right]\left(\mathrm{BF}_{4}\right)_{2}$ there

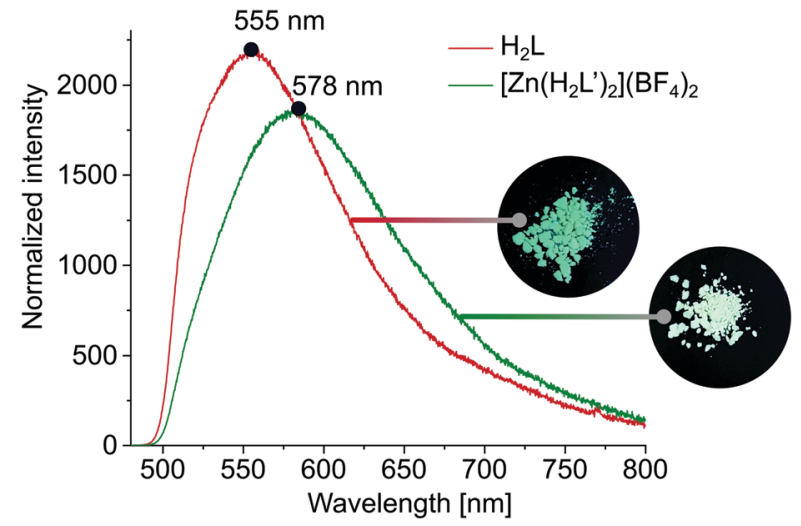

Fig. 4 Emission spectra of $\mathrm{H}_{2} \mathrm{~L}$ and $\left[\mathrm{Zn}\left(\mathrm{H}_{2} \mathrm{~L}^{\prime}\right)_{2}\right]\left(\mathrm{BF}_{4}\right)_{2}$ in the solid state, together with photographs made under UV light (254 nm).

is a notable shift in the band maximum $=578 \mathrm{~nm}$ (for absorbance spectra see ESI, $\dagger$ Fig. S12).

The difference in fluorescence under excitation at $254 \mathrm{~nm}$ is also visible to the naked eye as a slight difference in colour (Fig. 4). The observed significant Stokes shifts of $87 \mathrm{~nm}\left(\mathbf{H}_{2} \mathbf{L}\right)$ and $110 \mathrm{~nm}\left(\left[\mathrm{Zn}\left(\mathbf{H}_{2} \mathbf{L}^{\prime}\right)_{2}\right]\left(\mathrm{BF}_{4}\right)_{2}\right)$ predispose both materials to application as dynamic fluorescence dyes.

Due to the limited solubility of both $\mathbf{H}_{2} \mathbf{L}$ and $\left[\mathrm{Zn}\left(\mathbf{H}_{2} \mathbf{L}^{\prime}\right)_{2}\right]\left(\mathrm{BF}_{4}\right)_{2}$, we were not able to obtain a crystal suitable for an $\mathrm{X}$-ray diffraction measurement, even after multiple trials. However, computational methods are a powerful tool for compound characterization. Therefore the B3LYP/6-31+G(d,p) molecular geometry optimization of $\mathbf{H}_{2} \mathbf{L}$ together with $\mathbf{H}_{2} \mathbf{L}^{\prime}$ and $\left[\mathrm{Zn}\left(\mathbf{H}_{2} \mathbf{L}^{\prime}\right)_{2}\right]\left(\mathrm{BF}_{4}\right)_{2}$ was performed. Additionally, in order to capture the effects of dispersion interactions, the empirical Grimme GD3 dispersion parameters were used, supplemented by Becke-Johnson (BJ) damping. The accuracy of the method was tested by first optimizing $\mathbf{H}_{2} \mathbf{L}$, until results from the literature ${ }^{25}$ were reproduced (Table S3 in the $\mathrm{ESI} \dagger)$. $\mathrm{Zn}\left(\mathbf{H}_{2} \mathbf{L}^{\prime}\right)_{2}{ }^{2+}$ was optimized stepwise using the same method. First $\mathbf{H}_{2} \mathbf{L}^{\prime}$ was optimized and based on these results, the structure of the cation $\mathrm{Zn}\left(\mathbf{H}_{2} \mathbf{L}^{\prime}\right)_{2}{ }^{2+}$ was obtained. Ligand molecules coordinate the $\mathrm{Zn}^{2+}$ cation in their pyrimidine-pyridine pocket, the $\mathrm{Zn}$ center having the symmetry of a distorted tetrahedron with angles $\mathrm{N}\left(\right.$ pyr) $-\mathrm{Zn}-\mathrm{N}$ (pyr) $153^{\circ}, \mathrm{N}\left(\right.$ py)$-\mathrm{Zn}-\mathrm{N}\left(\right.$ py) $105^{\circ}$ and N(pyr) $-\mathrm{Zn}-\mathrm{N}($ py) $81.5^{\circ}$ and $\mathrm{Zn}-\mathrm{N}(\mathrm{py})$ and $\mathrm{Zn}-\mathrm{N}(\mathrm{pyr})$ bond lengths of $2.08 \AA$ and $2.01 \AA$ A, respectively (see ESI, $\dagger$ Section II for details).

Intrinsic properties of a molecule can be predicted from the energy levels of the HOMO and LUMO orbitals. The calculations showed a symmetrical pattern for the $\mathbf{H}_{2} \mathbf{L} \mathbf{M O}$, while the introduction of a metal ion caused a shift of the electron density in the HOMO towards the metal centre and a displacement of the LUMO to the outer region of the ligand (Table S2 in the ESI $\dagger$ ). It has been previously shown, that $\mathbf{H}_{2} \mathbf{L}$ forms both $2 \mathrm{D}$ arrays and helical polymer chains at a solid-liquid interface. ${ }^{25}$ Fig. 5a presents the STM image of a helical dynamer $\mathbf{H}_{2} \mathbf{L}$ dropcasted onto HOPG, heated up and imaged at room temperature. The measured period of the model structure is $\sim 25 \mathrm{~nm}-$ in agreement with the experimental value. In addition to helical structures, we also observed 2D molecular arrays shown in Fig. 5d, 

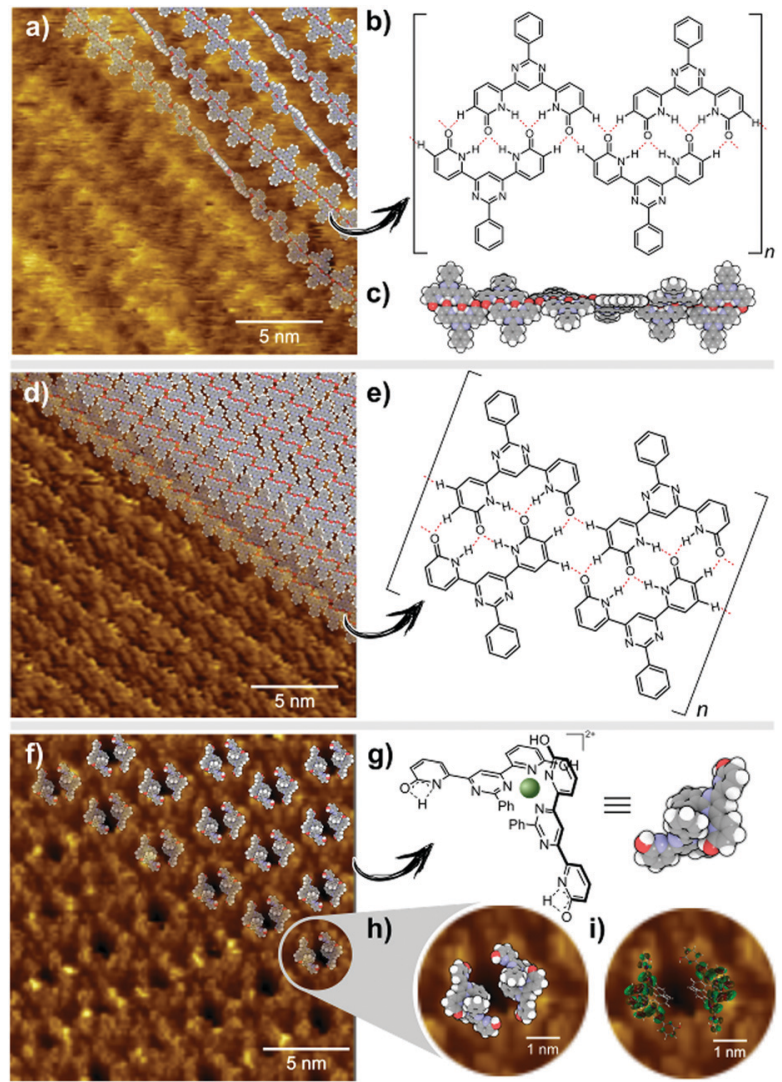

Fig. 5 (a) STM image of a helical dynamer with model arranged on top of it. Image size: $20 \times 20 \mathrm{~nm}^{2} ; V_{\text {sample }}=+0.6 \mathrm{~V} ; I_{T}=0.1 \mathrm{nA} ;(\mathrm{b})$ chemical structure of $\mathrm{H}_{2} \mathrm{~L}$ with presented $\mathrm{H}$-bond motif; (c) model of helical dynamer $\mathrm{H}_{2} \mathrm{~L}$; (d) STM image of a 2D array of dynamer with model an arranged on top of it Image size: $20 \times 20 \mathrm{~nm}^{2} ; V_{\text {sample }}=+0.6 \mathrm{~V} ; I_{\mathrm{T}}=0.1 \mathrm{nA}$; (e) chemical structure of $\mathrm{H}_{2} \mathrm{~L}$ with presented $\mathrm{H}$-bond motif; (f) STM image of 2D an array formed by complex $\left[\mathrm{Zn}\left(\mathrm{H}_{2} \mathrm{~L}^{\prime}\right)_{2}\right]\left(\mathrm{BF}_{4}\right)_{2}$ with a model arranged on top of it. Image size: $20 \times$ $20 \mathrm{~nm}^{2} ; V_{\text {sample }}=+0.6 \mathrm{~V} ; I_{\mathrm{T}}=0.1 \mathrm{nA} ;(\mathrm{g})$ chemical structure of the cation $\mathrm{Zn}\left(\mathrm{H}_{2} \mathrm{~L}^{\prime}\right)_{2}{ }^{2+}$ and its model; (h) zoomed area of STM image shown in (f). Image size: $5 \times 5 \mathrm{~nm}^{2} ; V_{\text {sample }}=+0.6 \mathrm{~V} ; I_{\mathrm{T}}=0.1 \mathrm{nA}$; (i) zoomed area of STM image with model of LUMO orbitals on top of it. Image size: $5 \times 5 \mathrm{~nm}^{2} ; V_{\text {sample }}=$ $+0.6 \mathrm{~V} ; I_{\mathrm{T}}=0.1 \mathrm{nA}$.

which are built from the same molecule $\mathbf{H}_{2} \mathbf{L}$ but with a different H-bonding motif (Fig. 5e). Following similar dropcasting of a solution of complex $\left[\mathrm{Zn}\left(\mathbf{H}_{2} \mathbf{L}^{\prime}\right)_{2}\right]\left(\mathrm{BF}_{4}\right)_{2}$, the STM image revealed a well-ordered molecular array, visible as a $2 \mathrm{D}$ array of dark spots surrounded by bright rings (Fig. 5f). The measured in-plane lattice parameters of this structure are $\sim 3.6 \mathrm{~nm}$. STM topography fits very well with the calculated LUMO orbitals of $\operatorname{Zn}\left(\mathbf{H}_{2} \mathbf{L}^{\prime}\right)_{2}{ }^{2+}$ (Fig. 5i). The two pyridone moieties not involved in coordination should still be able to form $\mathrm{H}$-bonds, regardless of their tautomeric form. This we consider to be the reason why two molecules of the complex assemble into toroidal dimer units (Fig. 5), which then form more extended arrays.

The present work provides a previously unknown example of the desymmetrisation of a ligand resulting from the metal-ioninduced tautomerisation of one binding site within an initially symmetrical organic species. This mode of coordination produces two different $\mathrm{H}$-bonding sites within the metallosupramolecular species, which are both used to provide different forms of association in the solid state and in solution. Retention of the amide form of the unbound coordination site is significant factor in leading to the H-bonding which appears to control the adsorbed form of the complex on the surface and which reveals its multifunctionality. Reversible interconversion between organic dynamer and metallosupramolecular toroidal species is readily achieved by simple control of metal ion concentration, base and acid additions and results in the generation of dynamic materials of distinct fluorescent properties. Thus, we have demonstrated that simple 2-pyridone derivatives are well suited for the generation of distinct forms of fluorescent adaptive materials.

\section{Conflicts of interest}

There are no conflicts to declare.

\section{Acknowledgements}

This work was funded by the National Science Centre of Poland grants: SONATA BIS 2018/30/E/ST5/00032 (A.R.S.), PRELUDIUM UMO-2016/21/N/ST5/00849 (W. D.) and OPUS 2014/15/B/ST3/ 02927 (Z. M. and M. L.). The work of P. C. was also co-financed by European Social Fund under the Operational Program Knowledge Education Development and Poznan Supercomputing and Networking Centre computing grant no. 401. The work of M. C. was co-financed by the National Centre for Research and Development grant POWR.03.02.00-00-I032/16. We thank Prof. Jean-Marie Lehn, Dr Monika Wałęsa-Chorab and Jakub Lewandowski for their contribution at the initial stage of this project.

\section{Notes and references}

1 J.-F. Lutz, J.-M. Lehn, E. W. Meijer and K. Matyjaszewski, Nat. Rev. Mater., 2016, 16024.

2 S. Chen, R. Costil, F. K. Leung and B. L. Feringa, Angew. Chem., Int. Ed., 2021, DOI: 10.1002/anie.202007693.

3 A. Goulet-Hanssens, F. Eisenreich and S. Hecht, Adv. Mater., 2020, 32, e1905966.

4 A. Brzechwa-Chodzyńska, M. Zieliński, M. Gilski, J. M. Harrowfield and A. R. Stefankiewicz, Inorg. Chem., 2020, 59, 8552-8561.

5 A. Bocian, W. Drożdż, M. Szymańska, J. Lewandowski, M. Fik-Jaskółka, A. Gorczyński, V. Patroniak and A. R. Stefankiewicz, Nanoscale, 2020, 12, 4743-4750.

6 G. Markiewicz, M. M. J. Smulders and A. R. Stefankiewicz, Adv. Sci., 2019, 6, 1900577.

7 W. Drożdż, A. Walczak, Y. Bessin, V. Gervais, X.-Y. Cao, J.-M. Lehn, S. Ulrich and A. R. Stefankiewicz, Chem. - Eur. J., 2018, 24, 10802-10811.

8 J. M. Lehn, Chem. Soc. Rev., 2007, 36, 151-160.

9 S. Sobczak, W. Drożdż, G. I. Lampronti, A. M. Belenguer, A. Katrusiak and A. R. Stefankiewicz, Chem. - Eur. J., 2018, 24, 8769-8773.

10 A. J. McConnell, C. S. Wood, P. P. Neelakandan and J. R. Nitschke, Chem. Rev., 2015, 115, 7729-7793. 
11 R. A. A. Abdine, G. Kurpik, A. Walczak, S. A. A. Aeash, A. R. Stefankiewicz, F. Monnier and M. Taillefer, J. Catal., 2019, 376, 119-122.

12 A. Walczak and A. R. Stefankiewicz, Inorg. Chem., 2018, 57, 471-477.

13 A. Walczak, H. Stachowiak, G. Kurpik, J. Kaźmierczak, G. Hreczycho and A. R. Stefankiewicz, J. Catal., 2019, 373, 139-146.

14 R. C. R. H. E. Toma, Croat. Chem. Acta, 2001, 499-528.

15 W. G. Jackson and A. M. Sargeson, Essay 11 in Rearrangements in Ground and Excited States, in Organic Chemistry: A Series of Monographs, ed. P. de Mayo, Academic Press, New York, 1980, vol. 42-3, pp. 273-378.

16 D. B. Brown, M. B. Robin and R. D. Burbank, J. Am. Chem. Soc., 1968, 90, 5621-5622.

17 D. P. Fairlie, T. C. Woon, W. A. Wickramasinghe and A. C. Willis, Inorg. Chem., 1994, 33, 6425-6428.

18 D. P. Fairlie, P. M. Angus, M. D. Fenn and W. G. Jackson, Inorg. Chem., 1991, 30, 1564-1569.
19 D. A. Decato and O. B. Berryman, Org. Chem. Front., 2019, 6, 1038-1043.

20 E. G. Witte, K. S. Schwochau, G. Henkel and B. Krebs, Inorg. Chim. Acta, 1984, 94, 323-331.

21 D. B. Amabilino and P. A. Gale, Chem. Soc. Rev., 2017, 46, 2376-2377.

22 T. Kudernac, S. Lei, J. A. Elemans and S. De Feyter, Chem. Soc. Rev., 2009, 38, 402-421.

23 M. W. Wong, K. B. Wiberg and M. J. Frisch, J. Am. Chem. Soc., 1992, 114, 1645-1652.

24 J. Seliger and V. Zagar, J. Phys. Chem. A, 2013, 117, 1651-1658.

25 A. Ciesielski, A. R. Stefankiewicz, F. Hanke, M. Persson, J.-M. Lehn and P. Samorì, Small, 2011, 7, 342-350.

26 Z. Xu, K. H. Baek, H. N. Kim, J. Cui, X. Qian, D. R. Spring, I. Shin and J. Yoon, J. Am. Chem. Soc., 2010, 132, 601-610.

27 C. G. Swain and J. F. Brown, J. Am. Chem. Soc., 1952, 74, 2538-2543.

28 P. J. Stang and B. Olenyuk, Acc. Chem. Res., 1997, 30, 502-518. 